\title{
Magnetic Abrasive Finishing for Inner surface of Al 6063 pipe: Experimental Investigations
}

\author{
Rui Wang ${ }^{+*}$, Pyo Lim and Sang Don Mun ${ }^{\dagger}$ \\ †, †Division of Mechanical Design Engineering, Chonbuk National University, 664-14, Duckjin-dong, Duckjin-gu, Jeonju, South Korea, 561-756 \\ ¥2 84, Wanam-ro, Seongsan-gu, Changwon-si, Gyeongsangnan-do, South Korea, 642-713
}

Accepted 21 June 2017, Available online 22 June 2017, Vol.7, No.3 (June 2017)

\begin{abstract}
The research aims to focus on the smooth surface of material, due to the development of the high technologies, in which a surface is finished by removing the material in the form of microchips by abrasive particles in the presence of magnetic field in the finishing zone. The inner surface of Al 6063 pipe was used as the workpiece and finished through a new improved mini lathe by using four experimental methods. The workpiece was finished by magnetic abrasive finishing (MAF) process in some different experimental methods such as, different magnetic abrasive mixed radios, different workpiece rotational speeds, different magnetic pole arrangements and different magnetic pole shapes, the best experimental combination in this study can be found by using the analysis of variance (ANOVA) and multiple comparisons. The experimental data were analyzed using analysis of variance and multiple comparisons to understand the contribution of various process factors on process response. Optical microscope images have been obtained to study the surface morphology of the finished workpiece. Regression model was developed to predict the trend of change in surface roughness in terms of significant experimental parameters.
\end{abstract}

Keywords: Magnetic abrasive finishing (MAF), Al 6063 pipe, Inner surface roughness, Analysis of variance (ANOVA), multiple comparisons

\section{Introduction}

With the rapid development of new technology that more and more demand on the excellence of the quality and performance of the product. High precision and compactness product are very high-profile in many areas. However, it is very difficult to make these high precision parts to achieve the satisfaction requirements in today's engineering industry. Especially, those based on the use of special needs and made into the shape of the material. Al 6063 pipe is the main medium for microwave conductivity, and it has been widely used in the electronics, navigation, communications and other fields. Due to the specialty of the usage conditions of the Al 6063 pipe, it is required that the dimensional accuracy of $\mathrm{Al} 6063$ pipe is very high while the roughness of the inner surface must be low enough. In the previous study, the researchers have applied many finishing techniques to improve the surface accuracy and dimensional accuracy of Al 6063 pipe. However, the surface roughness and the actual use, there is still a distance (L. Zhang et al, 2014). The researchers applied the heat treatment in cold-drawn processes to improve

*Corresponding author's ORCID ID: 0000-0002-6673-9671

DOI: http://Dx.Doi.Org/10.14741/Ijcet/22774106/7.3.2017.78 precision accuracy and mechanical properties (J. P.Bourget et al, 2009), but the precision of inner surface of the pipe has not been explicit data.

Magnetic abrasive finishing process is one of the unconventional finishing techniques, which the magnetic abrasive particles are used as a tool to abrade the workpiece surface to achieve extremely high quality surface finish (Sung Yoon et al, 2014). And this finishing technique is widely used to improve surface of manty different shape of workpiece, because the polishing tools composed of fine magnetic particles, which is flexible and easy to closely follow the finished surface. Yoon et al have study the effects of abrasive mixed ratios $(1: 1,3: 1,6: 1)$ and magnet pole arrangements ( $\mathrm{N}$ single, $\mathrm{N}-\mathrm{S} 90^{\circ}, \mathrm{N}-\mathrm{S} 180^{\circ}, \mathrm{N}-\mathrm{S}-\mathrm{N}$ ) on the inner surface of STS 304 pipe using magnetic abrasive finishing method and concluded that N-S-N magnetic pole arrangement and 3:1 are found to be the best condition in his study.

This main purpose of this study is to investigate the effects of some parameters such as, different abrasive mixed ratios, different workpiece rotational speeds, and different magnet abrasive finishing of Al 6063 . Analysis of Variance (ANOVA) and multiple comparisons has been used to determine significant experimental conditions of finishing process in terms of surface roughness. 


\section{Literature review}

Several MAF processes have been reported recently. Some of the significant literature was discussed below. Hitomi Yamaguchi has proposed the magnetic abrasive finishing of cutting tools for machining of titanium alloys. They used MAF method to improve the tool surface roughness with minimal material removal and the results showed that the magnetic particle brush is a critical factor. They also studied the relationships between surface conditions of AlTiN-coated round tools, cutting forces, and wear characteristics were clarified by milling of Ti-6Al-4V alloys. With their results they reported the roughness of coated tools was improved by $50-60 \%$ without deteriorating the cutting edge radius, and the tool life was extended by $150 \%$.

G. Y. Liu developed the processing aluminum combination of electrochemical machining (ECM) and magnetic abrasive finishing (MAF) method. He proposed the ECM process must cooperate with the MAF process and the ECM must be kept in the passivation status. He selected the optimal parameters to improve the surface roughness ( $\mathrm{Ra}$ ) from $1.3 \mu \mathrm{m}$ to $0.2 \mu \mathrm{m}$ in a few minutes.

Jinzhong $\mathrm{Wu}$ investigated the effect of alternating magnetic field on magnetic field distribution, the finishing force and the abrasive behavior in study on ultra-precision magnetic abrasive finishing process using low frequency alternating magnetic field. He designed the experimental devices in order to finishing SUS 304 stainless steel plate and concluded that the surface roughness of SUS 304 stainless steel plant was improved from $240.24 \mathrm{~nm}$ to $4.38 \mathrm{~nm}$.

The study is aimed to study the effect of critical parameters like magnetic abrasive mixed radio, rotational speed, magnetic pole arrangement, and magnetic pole shape on the inner surface magnetic abrasive finishing of $\mathrm{Al} 6063$ pipe. In order to perform the experiments of finishing process, the required setup was designed and confirmed. Optical microscope images of three-dimensional surface textures were taken to further analyze the results.

\section{Experimental set up}

Fig. 1 shows the experimental setup used for inner magnetic abrasive finishing process. As shown in Fig. 1 that the workpiece is fixed by a chuck on the spindle and it rotates as the spindle rotates. A magnetic abrasive tool is supplied to the inner surface of the workpiece, and several permanent magnets were arranged outside the workpiece. The magnetic vibration device consists of a proximity sensor, a motor, a linear slider, and a control unit. The magnitude and direction of the magnetic force acting on the magnetic abrasive particles depend on the magnetic pole arrangement. Processing action is performed by flexible magnetic abrasive brush, this brush through magnetic forces act on the inner surface of pipe.

\section{Experimental procedure}

In magnetic abrasive finishing process of the inner surface of the pipe, the \#320 magnetic abrasive materials and the \#200 iron particles were mechanically mixed in a specific ratio at 1:1 3:1 and $6: 1$. The finishing process of $\mathrm{Al} 6063$ pipe was performed with different workpiece revolution speeds at $400 \mathrm{rpm}, 800 \mathrm{rpm}, 1,200 \mathrm{rpm}$ and 1,600 rpm. The magnitude and direction of the magnetic force acting on the magnetic abrasive particles depend on the magnetic pole arrangement. Four magnetic pole arrangements were used in this study for comparison. It can be seen in Fig. 2, N single, N-S $90^{\circ}, \mathrm{N}-\mathrm{S} 180^{\circ}$ and $\mathrm{N}-\mathrm{S}-\mathrm{N}$ arrangements was carried out. Fig. 3 shows experimental conditions by four kinds of magnetic pole shape. Because account the shape of the magnetic pole different pole in the forces on the workpiece will be different.

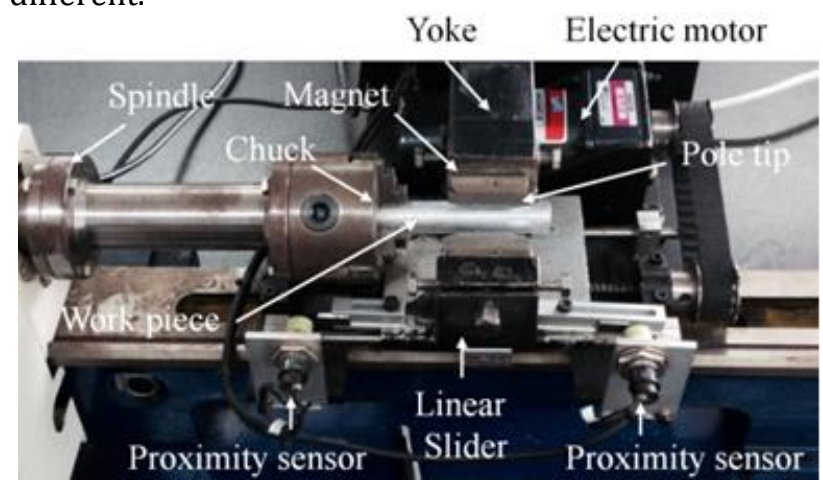

Fig.1 Photograph of magnetic abrasive finishing equipment
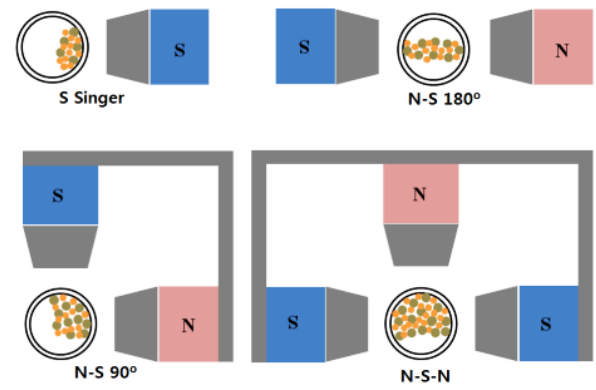

Fig.2 Experimental conditions by magnetic pole arrangement

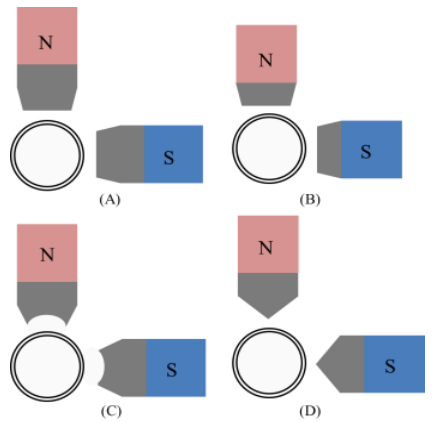

Fig.3 Experimental conditions by four kinds of magnetic pole shape 
Table 1 Details of process parameters

\begin{tabular}{|c|c|c|c|c|c|}
\hline \multirow{2}{*}{ Symbol } & \multirow{2}{*}{ Description } & \multicolumn{4}{|c|}{ Level } \\
\cline { 3 - 6 } & & 1 & 2 & 3 & 4 \\
\hline X1 & Abrasive mixed radio & $1: 1$ & $3: 1$ & $6: 1$ & - \\
\hline X2 & Rotational speed & 400 & 800 & 1,200 & 1,600 \\
\hline \multirow{2}{*}{ X3 } & Magnetic pole arrangement & \multirow{2}{*}{ N single } & $\begin{array}{c}\text { N-S } \\
90^{\circ}\end{array}$ & $\begin{array}{c}\text { N-S } \\
180^{\circ}\end{array}$ & N-S-N \\
\hline X4 & Magnetic pole shape & A & B & C & D \\
\hline
\end{tabular}

In order to analyze the performance of finishing process of the inner surface for Al 6063 pipe, four process parameters were selected like four different magnetic abrasive mixed ratios, four different workpiece rotational speeds, four different magnetic pole arrangements, and four different magnetic pole shapes. To decide the levels of these main influence parameters, some preliminary experiment was done. Also these experiments helped in deciding the finishing time for each experiment for five times per 2 minutes.

The details of process parameters are shown in table 1 experiment samples was not the same, thus this variation was taken into account by considering ratio of change in surface roughness to the initial surface roughness. But this variation was not substantial to affect the performance. The percentage improvement in surface roughness values was also calculated by the following equations Eq. (1).

$\Delta \mathrm{Ra}=\frac{\text { Intial Ra }- \text { Final Ra }}{\text { Fntial Ra }} \times 100 \%$

\section{Experimental analysis}

In order to find a better effect of experimental factor on change in surface roughness $(\Delta \mathrm{Ra})$, the experimental data obtained by experimental results was analyzed with analysis of variance (ANOVA) and multiple comparisons.

\section{Magnetic abrasive finishing characteristics of the mixed ratio}

Fig. 4 shows the analysis of variance (ANOVA) and multiple comparisons for the magnetic abrasive mixed ratio and finishing time in terms of the surface roughness (Ra). In terms of surface roughness, the 3:1 of mixed ratio is found to be the best condition followed by $1: 1$, and then $6: 1$. The finishing time at 6 minutes is found to be the critical factor for improving the surface roughness of workpiece. Table 2 shows the general linear model of finishing time and mixed radio. Table 3 shows the analysis of variance for delta Ra $(\mu \mathrm{m})$ and finishing time.

Table 2 General Linear Model: Ra versus Time, Mixed ratio

\begin{tabular}{|c|c|c|c|}
\hline Factor & Type & Levels & Values \\
\hline Time & Fixed & 6 & $0,2,4,6,8,10$ \\
\hline Mixed ratio & Fixed & 3 & $1,3,6$ \\
\hline
\end{tabular}

Table 3 Analysis of variance for Ra, using Adjusted SS for Tests

\begin{tabular}{|c|c|c|c|c|c|c|}
\hline Source & DF & Seq SS & Adj SS & Adj MS & F & P \\
\hline Time & 5 & 0.0340444 & 0.0340444 & 0.0068089 & 60.67 & 0.000 \\
\hline Mixed ratio & 2 & 0.0005444 & 0.0005444 & 0.0002722 & 2.43 & 0.138 \\
\hline Error & 10 & 0.0011222 & 0.0011222 & 0.0001122 & & \\
\hline Total & 17 & 0.0357111 & & & & \\
\hline
\end{tabular}

As shown in table 3 that the $P$ value of finishing time is less than 0.05. Thus, it could be confirmed that the finishing time is effective in improving the surface roughness of material. However, the $P$ value of magnetic abrasive mixed ratio is larger than 0.05 . Thus, it could be confirmed that the main factor of the mixed ratio was not significant. Because the $P$ value of finishing time is less than 0.05 in table 3 , so the results of finishing time was analyzed using Bonferroni method. In this processing, the processing time is significant to magnetic abrasive finishing process, the finishing time is used as the parameter and their results are shown in Table 4 . As shown in Table 4 that the processing time is divided into three groups.

Group $A$ is the value of surface roughness before finishing at 0 min and group B is the value of surface roughness after finishing at $2 \mathrm{~min}$ and $2 \mathrm{~min}$ is not the significant time on the factor of mixed ratio. Group $\mathrm{C}$ is the value of surface roughness after finishing at $(4,10$, 8 , and $6 \mathrm{~min}$ ). According to the results, the finishing time at $(4,10,8,6) \mathrm{min}$ are the useful parameters for this factor of finishing process, $6 \mathrm{~min}$ is optimal finishing time in factor of magnetic abrasive mixed ratio. 


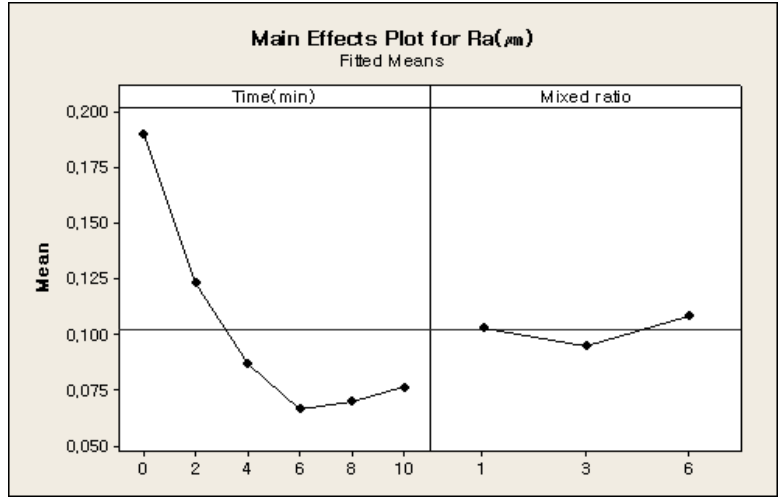

Fig.4 Main effects plot for Magnetic abrasive mixed ratio

Table 4 Mixed ratio VS TIME, (Grouping information sing Bonferroni Method and 95.0\% Confidence)

\begin{tabular}{|c|c|c|c|c|c|}
\hline Time (min) & $\mathrm{N}$ & Mean & \multicolumn{2}{|c|}{ Grouping } \\
\hline 0 & 3 & 0.19000 & $\mathrm{~A}$ & & \\
\hline 2 & 3 & 0.12333 & & $\mathrm{~B}$ & \\
\hline 4 & 3 & 0.08667 & & & $\mathrm{C}$ \\
\hline 10 & 3 & 0.07667 & & & $\mathrm{C}$ \\
\hline 8 & 3 & 0.07000 & & & $\mathrm{C}$ \\
\hline 6 & 3 & 0.06667 & & & $\mathrm{C}$ \\
\hline
\end{tabular}

Magnetic abrasive finishing characteristics of the mixed ratio

Fig. 5 shows the analysis of variance (ANOVA) and multiple comparisons for the workpiece rotational speed and finishing time in terms of the surface roughness $(\mathrm{Ra})$.

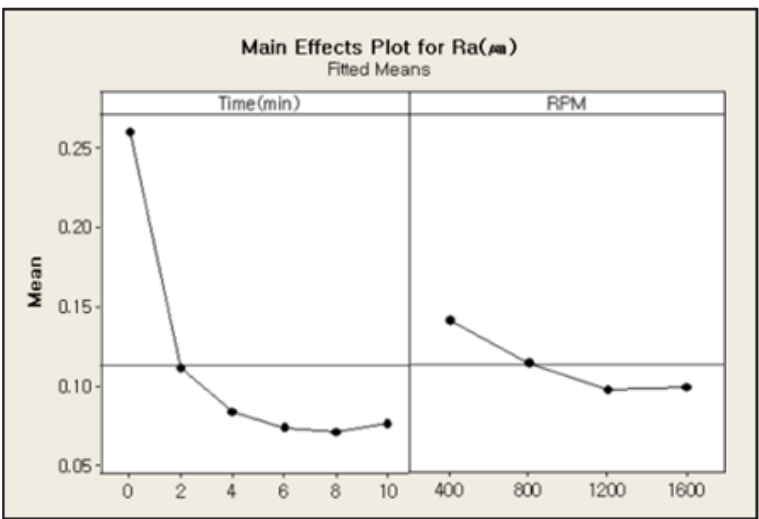

Fig.5 Main effects plot for rotational speed

In terms of surface roughness, the $1,200 \mathrm{rpm}$ of revolution speed is found to be the best condition followed by 1,600 rpm, $800 \mathrm{rpm}$, and then $400 \mathrm{rpm}$.

Table 5 General Linear Model: Ra versus Time, Rotational speed

\begin{tabular}{|c|c|c|c|}
\hline Factor & Type & Levels & Values \\
\hline Time & Fixed & 6 & $0,2,4,6,8,10$ \\
\hline Rpm & Fixed & 4 & $400,800,1,200,1,600$ \\
\hline
\end{tabular}

Table 6 Analysis of variance for delta Ra, using Adjusted SS for Tests

\begin{tabular}{|c|c|c|c|c|c|c|}
\hline Source & DF & Seq SS & Adj SS & Adj MS & F & P \\
\hline Time & 5 & 0.106938 & 0.106938 & 0.002415 & 3.30 & 0.049 \\
\hline Rpm & 3 & 0.007246 & 0.007246 & 0.021388 & 29.22 & 0.000 \\
\hline Error & 15 & 0.010979 & 0.010979 & 0.000372 & & \\
\hline Total & 23 & 0.125163 & & & & \\
\hline
\end{tabular}

The finishing time at 8 minutes is found to be the critical factor for improving the surface roughness of workpiece. Table 5 shows the general linear model of finishing time and rotational speed. Table 6 shows the analysis of variance for delta $\mathrm{Ra}(\mu \mathrm{m})$ and finishing time. As shown in table 6 that the $P$ value of rotational speed and finishing time are less than 0.05. Thus, it could be confirmed that the workpiece rotational speed and finishing time are effective in improving the surface roughness of material.

Table 6 shows the relationship between rotation speed and processing time. Because the $P$ value of rotational speed and finishing time are less than 0.05 in table 6 , so the results of finishing time and rotational speed were analyzed using Bonferroni method. In this processing, the processing time is significant to magnetic abrasive finishing process, so it is used as the parameter and their results are shown in Table 7.
As shown in Table 7 that the processing time is divided into two groups. Group A is the value of surface roughness before finishing at $0 \mathrm{~min}$ and group $\mathrm{B}$ is the value of surface roughness after finishing at $(2,4,10,8$ and $6 \mathrm{~min}$ ). According to the results, the finishing time at $(2,4,10,8$ and $6 \mathrm{~min})$ are the useful parameters for finishing process. $8 \mathrm{~min}$ is optimal finishing time in factor of rotational speed.

Table 7 Rotational speed (rpm) and processing time, (Grouping Information Using Bonferroni Method and 95.0\% Confidence)

\begin{tabular}{|c|c|c|c|c|}
\hline Time (min) & $\mathrm{N}$ & Mean & \multicolumn{2}{|c|}{ Grouping } \\
\hline 0 & 4 & 0.26000 & $\mathrm{~A}$ & \\
\hline 2 & 4 & 0.11250 & & $\mathrm{~B}$ \\
\hline 4 & 4 & 0.08500 & & $\mathrm{~B}$ \\
\hline 10 & 4 & 0.07750 & & $\mathrm{~B}$ \\
\hline 6 & 4 & 0.07500 & & $\mathrm{~B}$ \\
\hline 8 & 4 & 0.07250 & & $\mathrm{~B}$ \\
\hline
\end{tabular}


Table 8 Grouping Information Using Bonferroni Method and 95.0\% Confidence

\begin{tabular}{|c|c|c|c|}
\hline RPM & N & Mean & Grouping \\
\hline 400 & 6 & 0.14167 & A \\
\hline 800 & 6 & 0.11500 & A \\
\hline 1,600 & 6 & 0.10000 & A \\
\hline 1,200 & 6 & 0.09833 & A \\
\hline
\end{tabular}

Table 9 General Linear Model: Ra versus Time, Magnetic pole arrangement

\begin{tabular}{|c|c|c|c|}
\hline Factor & Type & Levels & Values \\
\hline Time & Fixed & 6 & $0,2,4,6,8,10$ \\
\hline Arrangement & Fixed & 4 & $\mathrm{~N}-\mathrm{S}-\mathrm{N}, \mathrm{N}-\mathrm{S} 180^{\circ}, \mathrm{N}-\mathrm{S} 90^{\circ}$, N Singer \\
\hline
\end{tabular}

Table 10 Analysis of variance for Ra, using Adjusted SS for Tests

\begin{tabular}{|c|c|c|c|c|c|c|}
\hline Source & DF & Seq SS & Adj SS & Adj MS & F & P \\
\hline Time & 5 & 0.0657708 & 0.0657708 & 0.0131542 & 87.86 & 0.000 \\
\hline $\begin{array}{c}\text { Magnetic pole } \\
\text { arrangement }\end{array}$ & 3 & 0.0025792 & 0.0025792 & 0.0008579 & 5.74 & 0.008 \\
\hline Error & 15 & 0.0022458 & 0.0022458 & 0.0001497 & & \\
\hline Total & 23 & 0.0705958 & & & & \\
\hline
\end{tabular}

Magnetic abrasive finishing characteristics of magnetic pole arrangement

Fig. 6 shows the analysis of variance (ANOVA) and multiple comparisons for magnetic pole arrangement and finishing time in terms of the surface roughness $(\mathrm{Ra})$.

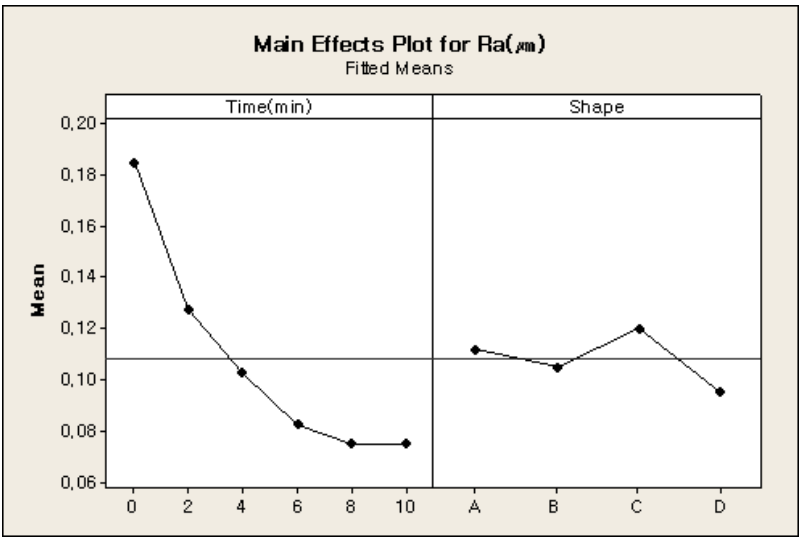

Fig.6 Main effects plot for Magnetic pole arrangement

In terms of surface roughness, the N-S-N of magnetic pole arrangement is found to be the best condition followed by N-S $180^{\circ}, \mathrm{N}$ single, and then N-S $90^{\circ}$. The finishing time at 6 minutes is found to be the critical factor for improving the surface roughness of workpiece. Table 9 shows the general linear model of finishing time and magnetic pole arrangement. Table 10 shows the analysis of variance for delta Ra $(\mu \mathrm{m})$ and finishing time. As shown in table 10 that the $\mathrm{P}$ value of magnetic pole arrangement and finishing time are less than 0.05. Thus, it could be confirmed that the magnetic pole arrangement and finishing time are effective in improving the surface roughness of material. Table 10 shows the relationship between magnetic pole arrangement and processing time. As the result in Table $10 \mathrm{P}$ value of magnetic pole arrangement and finishing time also are less than 0.05 , so the results of magnetic pole arrangement and finishing time were analyzed using Bonferroni method. Because the processing time is significant to magnetic abrasive finishing process, thus it is used as the parameter in this study and their results are shown in Table 11. As shown in Table 11 that the processing time is divided into three groups (group A, B, and C). Group $A$ is the value of surface roughness before finishing at 0 min. Group B is the value of surface roughness after finishing at $2 \mathrm{~min}$, and group $\mathrm{C}$ is the value of surface roughness after finishing at $(4,10,8$, $6 \mathrm{~min})$. According to the results, the finishing time at (4, $10,8,6 \mathrm{~min}$ ) are the useful parameters for finishing process. $6 \mathrm{~min}$ is optimal finishing time in factor of magnetic pole arrangement. Table 12 shows that the magnetic pole arrangement of the processing, so the result of magnetic pole arrangement was analyzed. As shown in Table 12 that the fours kind of magnetic pole arrangement is divided into two groups. According to the results, group $\mathrm{A}$ is the value of surface roughness at magnetic pole arrangement of N-S 90, N-Singer and N-S 180 , group $B$ is the value of surface roughness at magnetic pole arrangement of N Singer, N-S 180, N-S-N. So, four kinds of magnetic pole arrangement are the useful parameters for finishing process. And then surface roughness value of $\mathrm{N}-\mathrm{S} 90, \mathrm{~N}$-Singer and $\mathrm{N}-\mathrm{S}$ 180 were similar and surface roughness value of $\mathrm{N}$ Singer, N-S 180, N-S-N were similar.

Magnetic abrasive finishing characteristics of magnetic polo shape

Fig. 7 shows the analysis of variance (ANOVA) and multiple comparisons for magnetic pole shape and finishing time in terms of the surface roughness (Ra). 
Table 12 Grouping information using Bonferroni Method and 95.0\% Confidence

\begin{tabular}{|c|c|c|c|c|}
\hline Arrangement & $\mathrm{N}$ & Mean & \multicolumn{2}{|c|}{ Grouping } \\
\hline N-S 90음 & 6 & 0.10833 & $\mathrm{~A}$ & \\
\hline N Single & 6 & 0.10000 & $\mathrm{~A}$ & B \\
\hline N-S 180음 & 6 & 0.09333 & $\mathrm{~A}$ & $\mathrm{~B}$ \\
\hline N-S-N & 6 & 0.08000 & & B \\
\hline
\end{tabular}

Table 13 General Linear Model: Ra versus Time, Magnetic pole shape

\begin{tabular}{|c|c|c|c|}
\hline Factor & Type & Levels & Values \\
\hline Time & Fixed & 6 & $0,2,4,6,8,10$ \\
\hline Arrangement & Fixed & 4 & A, B, C, D \\
\hline
\end{tabular}

Table 14 Analysis of variance for Ra, using Adjusted SS for Tests

\begin{tabular}{|c|c|c|c|c|c|c|}
\hline Source & DF & Seq SS & Adj SS & Adj MS & F & P \\
\hline Time & 5 & 0.0366708 & 0.0657708 & 0.0073342 & 29.63 & 0.000 \\
\hline Shape & 3 & 0.0020125 & 0.0020125 & 0.0006708 & 2.71 & 0.082 \\
\hline Error & 15 & 0.0037125 & 0.0037125 & 0.0002475 & & \\
\hline Total & 23 & 0.0423958 & & & & \\
\hline
\end{tabular}

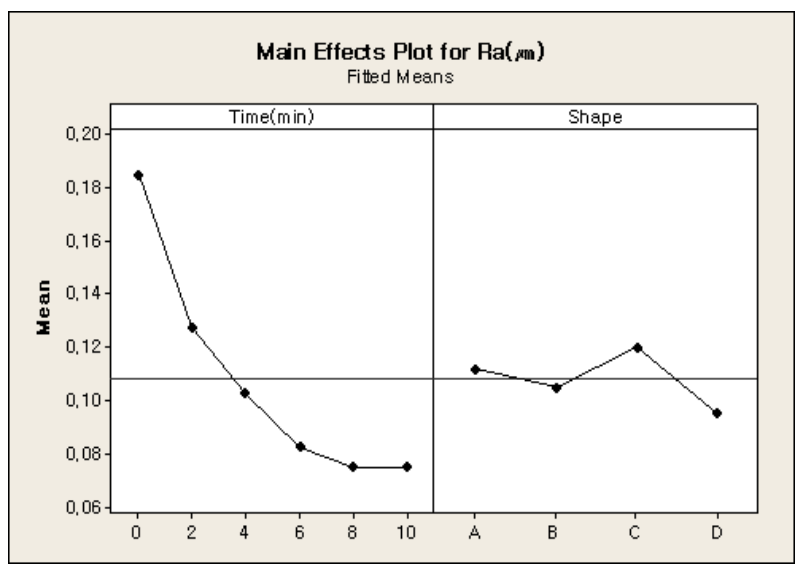

Fig.7 Main effects plot for magnetic pole shape

In terms of surface roughness, the D-shape of magnetic pole is found to be the best condition followed by Ashape, B-shape, and then $\mathrm{C}$-shape. The finishing time at 8 minutes are found to be the critical factor for improving the surface roughness of workpiece. Table 13 shows the general linear model of finishing time and magnetic pole shape. Table 14 shows the analysis of variance for delta $\mathrm{Ra}(\mu \mathrm{m})$ and finishing time. As shown in table 14 that the $\mathrm{P}$ value of finishing time is less than 0.05 . Thus, it could be confirmed that the finishing time is effective in improving the surface roughness of material. However, the $P$ value of magnetic pole shape is larger than 0.05 . Thus, it could be confirmed that the main factor of the magnetic pole shape was not significant. Because the $P$ value of finishing time is less than 0.05 in Table 14 , so the results of finishing time was analyzed using Bonferroni method. In this processing, the finishing time is used as the parameter and their results are shown in Table 15. As shown in Table 15 that the processing time is divided into three groups (group A, B and C). Group A is the value of surface roughness before finishing at 0 min. Group B is the value of surface roughness after finishing at 2 and $4 \mathrm{~min}$, and group $C$ is the value of surface roughness after finishing at $(4,6,10,8 \mathrm{~min})$ According to the results, the finishing time at $(4,6,10$, $8 \mathrm{~min}$ ) are the useful parameters for finishing process. $8 \mathrm{~min}$ is optimal finishing time in factor of magnetic pole shape.

Table 15 Magnetic polo shape and processing, (Grouping Information Using Bonferroni Method and 95.0\% Confidence)

\begin{tabular}{|c|c|c|c|c|c|}
\hline Time (min) & $\mathrm{N}$ & Mean & \multicolumn{3}{|c|}{ Grouping } \\
\hline 0 & 4 & 0.18500 & $\mathrm{~A}$ & & \\
\hline 2 & 4 & 0.12750 & & $\mathrm{~B}$ & \\
\hline 4 & 4 & 0.10250 & & $\mathrm{~B}$ & $\mathrm{C}$ \\
\hline 6 & 4 & 0.08250 & & & $\mathrm{C}$ \\
\hline 10 & 4 & 0.07500 & & & $\mathrm{C}$ \\
\hline 8 & 4 & 0.07500 & & & $\mathrm{C}$ \\
\hline
\end{tabular}

\section{Results and discussion}

\section{Effect of process factors on $\Delta_{a}$}

The main effect plot of the process is shown in Fig. 4, Fig. 5, Fig. 6 and Fig. 7. Fig. 4 shows the relationship between changes in surface roughness and magnetic abrasive mixture ratios. The weight ratios of iron particles and magnetic abrasive were $1: 1,3: 1$, and $6: 1$. It is likely that the abrasive mixture with a $3: 1$ mixing ratio in terms of the surface roughness ( $\mathrm{Ra}$ ) is better than two other conditions. In the case of conversion the rotation speeds, it can be seen from Fig. 5 that $\mathrm{Ra}$ linearly increasing relation with rotational speed of spindle. This because at higher rotational speed, the rate at which magnetic abrasive particles hit the workpiece inner surface strongly. Thus, the centrifugal force is increased. The best surface finish was achieved with 1,200 rpm. To study the effect of the magnetic 
pole arrangement in terms of the surface roughness, the different magnetic pole arrangements were used such as, $\mathrm{N}$ single, $\mathrm{N}-\mathrm{S} 90^{\circ}, \mathrm{N}-\mathrm{S} 180^{\circ}, \mathrm{N}-\mathrm{S}-\mathrm{N}$. Fig. 6 shows the variation in surface roughness for four kinds of different magnetic pole arrangements.

The surface roughness $(\mathrm{Ra})$ of workpiece was improved with four different magnetic pole arrangements. It can be found that the best surface roughness was significantly improved with N-S-N magnetic pole arrangement, and in this condition, when workpiece rotates, magnetic abrasives effect on the surface area becomes larger than other conditions, and finishing force becomes larger too. Therefore, the effectiveness of the N-S-N arrangement is likely due to the fact that it offers a large abrasion area and a higher pressing force. Fig. 7 shows the variation in surface roughness for four kinds of different magnetic pole shape. Taking into account the shape of the magnetic pole different role in the forces on the workpiece will be different; four different magnetic pole shapes were designed. Therefore, the effectiveness of the D-shape of magnetic pole is likely due to the fact that it sharp type with a higher pressing force.

\section{Optimization of objective function}

By observing the main effect plot effect of various process parameters on $\Delta \mathrm{Ra}$ is analyzed. Based on the results, a set of optimum process parameter were selected and experiment was performed using this data for finishing inner surface of $\mathrm{Al} 6063$ pipe. The optimum result obtained with the experiment is shown in Table 10. Fig. 8 shows the surface roughness profile of the same sample after finishing with optimum set of parameters. To support the analysis, using a noncontact type optical microscope and digital camera to measured before and after finishing of surface roughness. The surface roughness was from $0.35 \mu \mathrm{m}$ (Ra) to $0.04 \mu \mathrm{m}(\mathrm{Ra})$

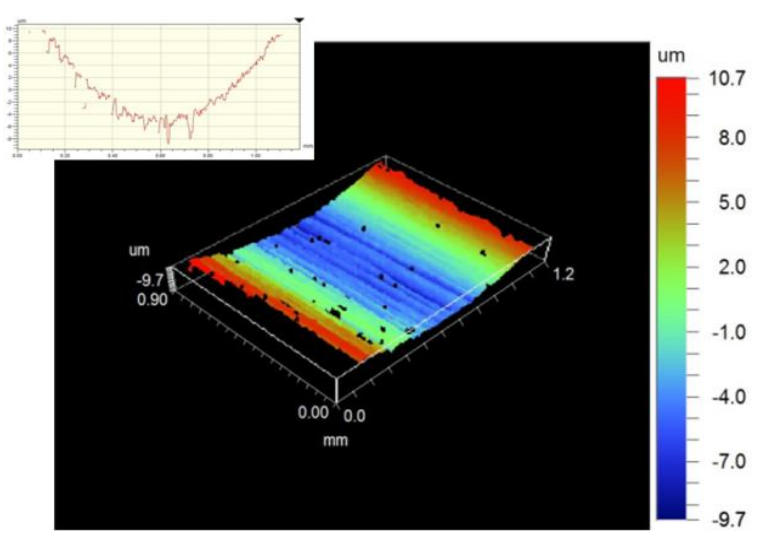

(a) Al 6063 pipe inner surface of before the polishing, Ra: $0.35 \mu \mathrm{m}$

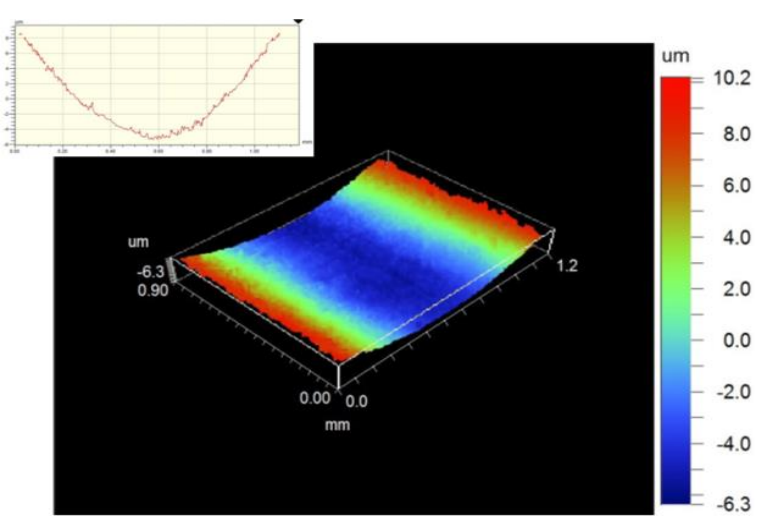

(b) Al 6063 pipe inner surface of after the polishing, Ra: $0.04 \mu \mathrm{m}$

Table 16 Optimization results for $\mathrm{Al} 6063$ pipe

\begin{tabular}{|c|c|}
\hline Sample & Al 6063 pipe \\
\hline Mixed radio & $3: 1$ \\
\hline Rotation speed (rpm) & 1,200 \\
\hline $\begin{array}{c}\text { Magnetic Arrangement } \\
\left(\mathrm{N} \text { single, N-S } 90^{\circ}, \mathrm{N}-\mathrm{S} 180^{\circ}, \mathrm{N}-\mathrm{S}-\mathrm{N}\right)\end{array}$ & $\mathrm{N}-\mathrm{S}-\mathrm{N}$ \\
\hline $\begin{array}{c}\text { Magnetic pole shape } \\
(\mathrm{A}, \mathrm{B}, \mathrm{C}, \mathrm{D})\end{array}$ & $\mathrm{D}$ \\
\hline
\end{tabular}

\section{Conclusions}

- In this research, the inner surface of Al 6063 pipe is successfully finished by using the magnetic abrasive finishing method.

- In four kinds of experimental methods, the best experimental condition can be found by using analysis of variance (ANOVA). The best condition in this study is $3: 1$ of magnetic abrasive mixed radio, $\mathrm{N}-\mathrm{S}-\mathrm{N}$ pole arrangement, 1,200 rpm of workpiece revolution speed, and using " $\mathrm{D}$ " Magnetic pole shape.

- Follow by the optimum conditions, inner surface roughness $\mathrm{Ra}$ is improved from $0.35 \mu \mathrm{m}$ to $0.04 \mu \mathrm{m}$ for 6-8 minutes.

\section{Acknowledgments}

This research was supported by Basic Science Research Program through the National Research Foundation of Korea (NRF) funded by the Ministry of Education (NRF-2016R1D1A1B03932103)

\section{References}

L. Zhang (2014) Research on the Inner Surface Roughness of the High Qualified Aluminum Rectangular Tube during Cold Drawing Process, China Master's Full-text Database.

J.-P. Bourget, M. Fafard, H. R. Shakeri, T.Cote (2009) Optimization of heat treatment in cold-drawn 6063 aluminum tubes, Journal of Materials Processing Technology, 209, 5035-5041.

Sung Yoon, Juei-Feng Tu, Jun Ho Lee, Gyun Eui Yang, Sang Don Mun (2014) Effect of the Magnetic Pole Arrangement on the Surface Roughness of STS 304 by Magnetic Abrasive 
Machining, International Journal of Precision Engineering and Manufacturing, 15.7, 1275-1281.

Junmo Kang, Hitomi Yamaguchi (2012) Internal finishing of capillary tubes by magnetic abrasive finishing using a multiple pole-tip system, Precision Engineering, 36, 510516.

Junmo Kang, Andrew George, Hitomi Yamaguchi (2012) High-speed Internal Finishing of Capillary Tubes by Magnetic Abrasive Finishing, 5th CIRP Conference on High Performance Cutting 2012, Procedia CIRP 1, 414-418.

Sang-Don Mun (2010) Micro machining of high-hardness materials using magnetic abrasive grains, International Journal of Precision Engineering and Manufacturing, 11.5, 763-770.

Dhirendra k. Singh, C. K. Jain, V. Raghuram, R. Komanduri (2005) Analysis of surface texture generated by a flexible magnetic abrasive brush, wear, 259, 1254-1261.

Jae-Seob Kwak (2009) Enhanced magnetic abrasive polishing of non-ferrous metals utilizing a permanent magnet, International Journal of Machine Tools \& Manufacture, 49, 613-618.
Hitomi Yamaguchi (2012) Anil K. Srivastava, Michael A. Tan, Raul E. Riveros, Fukuo Hashimoto, Magnetic abrasive finishing of cutting tools for machining of titanium alloys, CIRP Annals-Manufacturing Technology, 61, 311-314.

Shaohui Yin, Takeo Shinmura (2004) Acomparative study: polishing characteristics and its mechanisms of three vibration modes in vibration-assisted magnetic abrasive polishing, International Journal of Machine Tools \& Manufacture 44, 383-390.

Jinzhong Wu, Yanhua Zou, Hitoshi Sugiyama (2015) Study on ultra-precision magnetic abrasive finishing process using low frequency alternating magnetic field, Journal of Magnetic and Magnetic Materials, 386, 50-59.

Hitomi Yamaguchi (2012) Anil K. Srivastava, Michael A. Tan, Raul E. Riveros, Fukuo Hashimoto, Magnetic abrasive finishing of cutting tools for machining of titanium alloys, CIRP Annals-Manufacturing Technology, 61,311-314.

G.Y. Liu, Z.N. Guo, S.Z. Jiang, N.S. Qu, Y.B. Li (2014) A study of processing $\mathrm{Al} 6061$ with electrochemical magnetic abrasive finishing, Procedia CIRP, 14, 234-238. 